Journal Club

Editor's Note: These short reviews of recent JNeurosci articles, written exclusively by students or postdoctoral fellows, summarize the important findings of the paper and provide additional insight and commentary. If the authors of the highlighted article have written a response to the Journal Club, the response can be found by viewing the Journal Club at www.jneurosci.org. For more information on the format, review process, and purpose of Journal Club articles, please see http://jneurosci.org/content/ preparing-manuscript\#journalclub.

\title{
Stress-Related Memory Impairments Are Modulated by the Synergistic Action of Stress Hormones: Implications for PTSD
}

\author{
- Natalie Matosin and $\mathbb{C C}^{-}$ristiana Cruceanu \\ Department of Translational Research in Psychiatry, Max-Planck Institute of Psychiatry, 80804 Munich, Germany \\ Review of Chen et al.
}

Stress constitutes an organism's essential physiological response to the environment, and it exerts variable influences on memory depending on the context, type, and duration of the stressor (Vogel and Schwabe, 2016). Generally, acute stressors are thought to boost memory formation, possibly as a survival mechanism, whereas exposure to chronic stress is associated with impaired memory formation, or stress-induced amnesia. This phenomenon is believed to be a defense mechanism to reduce psychological damage caused by excessive adversity.

Stress is the leading risk factor for the development of a broad range of severe psychiatric conditions, including post-traumatic stress disorder (PTSD). PTSD affects $\sim 6 \%-7 \%$ of the U.S. population (Gradus, 2016), and it develops after a traumatic event or series of stressors, including sexual assault, extreme violence or war, traffic accidents, or another threat to one's life (Kessler et al., 2005). Prominent memory disturbances are a central feature of PTSD and are

Received Dec. 31, 2016; revised March 11, 2017; accepted March 16, 2017. N.M. was supported by NHMRC Early Career Fellowship 1105445. We thank our mentor, Dr. Elisabeth Binder.

The authors declare no competing financial interests.

Correspondence should be addressed to either Dr. Natalie Matosin or Dr. Cristiana Cruceanu, Department of Translational Research in Psychiatry, Max Planck Institute of Psychiatry, Kraepelinstrasse 2-10, 80804 Munich, Germany. E-mail: natalie_matosin@psych.mpg.de or cristiana_cruceanu@psych.mpg.de.

DOI:10.1523/JNEUROSCI.3980-16.2017

Copyright $\odot 2017$ the authors $\quad 0270-6474 / 17 / 374225-03 \$ 15.00 / 0$ part of the diagnostic criteria for the illness (American Psychiatric Association, 2000). For this reason, many PTSD studies have explored the effects of stress on the hippocampus, the primary brain structure involved in memory formation. Hippocampal atrophy and marked deficits in hippocampal-dependent recall, declarative memory, and spatial memory are commonly described in PTSD (Karl et al., 2006; Samuelson, 2011). However, the neurochemical pathways that lead to impaired hippocampal-dependent memory are not comprehensively understood.

Landmark studies have highlighted the importance of the major stress hormones corticotrophin-releasing hormone (CRH) and cortisol in stress in general, and PTSD in particular. CRH, released by the hypothalamus, activates the release of ACTH from the pituitary gland. ACTH is transported through the blood to the adrenal gland where it stimulates the production of glucocorticoid hormones (mainly cortisol in humans, and its homolog corticosterone [CORT] in mice). Cortisol, among its many effects, acts in a negative feedback loop to suppress CRH release from the hypothalamus and suppress ACTH release from the pituitary gland. This complex interaction between the three endocrine glands is known as the hypothalamic-pituitary-adrenal axis, and it is the major mechanism by which the body responds to stress.
Hypersecretion of CRH and cortisol are linked to inappropriate stress-coping abilities that in the long term can contribute to the development of stress- and traumainduced disorders (Lehrner et al., 2016). Receptors for cortisol, and consequently its effects, are ubiquitous. In contrast, $\mathrm{CRH}$ receptors are not as extensively expressed, and the main function of $\mathrm{CRH}$ is to stimulate pituitary synthesis of ACTH. However, $\mathrm{CRH}$ receptor density is also relatively high in brain regions essential for mediating fear, stress, and memory, such as the hippocampus (Justice et al., 2008). Moreover, high levels of CRH have been detected in the CSF of patients with PTSD, and levels are correlated with symptom severity (de Kloet et al., 2007). Although levels of CRH are higher in patients with PTSD than in trauma-exposed individuals without PTSD, no differences in cortisol levels are observed (de Kloet et al., 2007). Given that local CRH stores in the hippocampus are released in response to stress (Chen et al., 2004), recent research has focused on the interactions of cortisol/CORT and CRH in modulating memory function under adverse conditions.

Recent work in The Journal of Neuroscience by Chen et al. (2016) elucidated some of the subtleties of stress-induced spatial memory disturbances regulated by $\mathrm{CRH}$ and CORT. The authors studied mice exposed to 1-2 $\mathrm{h}$ of multiple simultaneous acute 
stressors, including restraint, bright light, unpredictable loud noises, physical jostling, and being aware of peer discomfort. Consistent with previous work (Maras et al., 2014), this stress paradigm impaired spatial memory, reduced LTP, and diminished dendritic spine density in the CA1 region of the hippocampus. This impairment in spatial memory appeared quite stable, as mice allowed to recover for $24 \mathrm{~h}$ to a week following the stress had persistently impaired spatial memory function, with diminished performance in the novel object recognition spatial memory task. The effects of multiple stress exposure on spine density and plasticity were then recapitulated by neuroendocrine manipulation to indicate that the synergistic actions of CRH and CORT mediate these long-lasting effects of acute concurrent stresses on memory (Chen et al., 2016).

CRH and CORT are highly concentrated in the hippocampus in conditions of stress, and the work by Chen et al. (2016) suggests that it is the dual action of the hormones that contributes to suppression of synaptic plasticity and impairment of memory. When hippocampal slices were treated with CORT and CRH alone, synaptic responses were not changed to a significant degree. But when hippocampal slices were treated with the hormones together, they produced a rapid and profound decrease in synaptic activity. Furthermore, whereas CORT alone had no effect on spine density and CRH only marginally decreased spine density, the combination of both hormones recapitulated the full effect of multiple stressors on spine density (Chen et al., 2016).

Filamentous actin is the backbone of dendritic spines, and thus proteins that control the polymerization of actin can either promote spine remodeling or cause spine destruction. One modulator of filamentous actin is RhoA, a small Rho GTPase protein that enables actin remodeling (Kramár et al., 2009). Previous work indicated that CORT reduced activity of RhoA (Jafari et al., 2012), whereas Calpain1, a protein that degrades RhoA (Briz et al., 2015), was activated by $\mathrm{CRH}$. Consistent with this, Chen et al. (2016) found that CORT alone did not significantly reduce the density of RhoApositive spines, whereas $\mathrm{CRH}$ alone exerted a moderate spine reduction. Only together could CRH and CORT cause degradation of filamentous actin polymers and the observed reduction in dendritic spines associated with active RhoA. These findings support the hypothesis that the combined action of CORT and CRH on the RhoA pathway underlies stress-mediated disrup- tion of dendritic spine structure in the hippocampus to cause lasting memory deficits.

A major benefit of studying stress in rodent models is the ability to identify specific mechanisms that are difficult to study in heterogeneous human populations that have many confounding factors. However, an important consideration when translating results from rodent models to human conditions is that in humans, such mechanisms rarely appear in isolation. The nature of the stressor can determine the regions of the brain involved and how that region is physiologically affected, with such effects extending beyond the hippocampus. For example, repetitive, mild, and short-lasting stressors may cause a reduction of prefrontal cortex-dependent cognitive function (Arnsten, 2009). Exposure to chronic and more severe stress has been shown to cause architectural changes in relevant brain regions, such as reduced thickness of the somatosensory cortex covering the gonadal regions in those exposed to sexual abuse (Heim et al., 2013). Thus, a challenge for researchers is to balance our understanding of individual mechanisms uncovered in preclinical models and bring these into the context of complex human conditions.

Memory deficits are not always observed in individuals exposed to trauma, with some even experiencing post-traumatic growth (Shakespeare-Finch and Lurie-Beck, 2014). It has been suggested that risk and resilience to PTSD or post-traumatic growth depend on a background of genetic vulnerability, but also personality or individuality (Kim and Diamond, 2002). Unfortunately, animal studies, such as the work by Chen et al. (2016), cannot model all the intricate complexities of human stress-induced psychiatric disorders. These include polygenic risk, long-term epigenetic modifications, and differences in perception and processing dependent on human personality and identity. Recent research is beginning to explore the role of individuality in preclinical models (Freund et al., 2013), which may be interesting for further revealing mechanisms and perhaps delineating (1) subgroups of people who are vulnerable or resilient to PTSD, and/or (2) PTSD subgroups who may be characterized by a defined pathology (e.g., reduced CRH and cortisol in the hippocampus) and therefore responsive to certain pharmacological strategies.

Although previous literature is clear in defining the negative effects of chronic stress on memory formation, Chen et al. (2016) additionally established a negative role for multiple simultaneous acute stressors that are milder individually. Subsequent exploration of the dual effect of CRH and cortisol/
CORT in response to a single major stressful event or during chronic stress would be an important next step. Many PTSD cases are triggered by a major acute stress, such as rape, other forms of nonsexual violence, or accidents. In these instances, it is unclear whether memory formation would be enhanced or impaired, and whether these effects are mediated through the dual action of both stress hormones. These findings will thus benefit from extension into different stress paradigms, human cohorts, and postmortem brains from individuals with a history of childhood adversity or PTSD.

Chen et al. (2016) establish a role for $\mathrm{CRH}$ and CORT, their interactive actions and effects on hippocampal physiology in disrupting spatial memory formation following multiple acute stressors. Their work bridges basic research to potential clinical interventions, for example, pharmacologically accessing and reconsolidating traumatic memories that contribute to the symptoms of stress-related psychiatric disorders (e.g., Sandrini et al., 2015). Furthermore, while Chen et al. (2016) showed the dual actions of stress hormones contributes to spatial memory impairments lasting days after multiple acute stressors, it would be of translational value for future studies to determine whether these memory deficits are longer-lasting, considering that a hallmark of PTSD is sustained memory deficits that can last for years after a traumatic event (Samuelson, 2011).

\section{References}

American Psychiatric Association (2000) Diagnostic and statistical manual of mental disorders (DSM-IV-TR). Arlington, VA: American Psychiatric Association.

Arnsten AF (2009) Stress signalling pathways that impair prefrontal cortex structure and function. Nat Rev Neurosci 10:410-422. CrossRef Medline

Briz V, Zhu G, Wang Y, Liu Y, Avetisyan M, Bi X, Baudry M (2015) Activity-dependent rapid local RhoA synthesis is required for hippocampal synaptic plasticity. J Neurosci 35: 2269-2282. CrossRef Medline

Chen Y, Brunson KL, Adelmann G, Bender RA, Frotscher M, Baram TZ (2004) Hippocampal corticotropin releasing hormone: pre- and postsynaptic location and release by stress. Neuroscience 126:533-540. CrossRef Medline

Chen Y, Molet J, Lauterborn JC, Trieu BH, Bolton JL, Patterson KP, Gall CM, Lynch G, Baram TZ (2016) Converging, synergistic actions of multiple stress hormones mediate enduring memory impairments after acute simultaneous stresses. J Neurosci 36:11295-11307. CrossRef Medline

de Kloet CS, Vermetten E, Geuze E, Lentjes EG, Heijnen CJ, Stalla GK, Westenberg HG (2007) Elevated plasma corticotrophin-releasing hormone levels in veterans with posttraumatic stress disorder. In: Progress in brain research (de 
Kloet ER, ed), pp 287-291. Stress Hormones and Post Traumatic Stress Disorder Basic Studies and Clinical Perspectives. Amsterdam: Elsevier.

Freund J, Brandmaier AM, Lewejohann L, Kirste I, Kritzler M, Krüger A, Sachser N, Lindenberger U, Kempermann G (2013) Emergence of individuality in genetically identical mice. Science 340:756-759. CrossRef Medline

Gradus J (2016) Epidemiology of PTSD-PTSD: National Center for PTSD. US Department of Veterans Affairs.

Heim CM, Mayberg HS, Mletzko T, Nemeroff CB, Pruessner JC (2013) Decreased cortical representation of genital somatosensory field after childhood sexual abuse. Am J Psychiatry 170:616-623. CrossRef Medline

Jafari M, Seese RR, Babayan AH, Gall CM, Lauterborn JC (2012) Glucocorticoid receptors are localized to dendritic spines and influence local actin signaling. Mol Neurobiol 46:304315. CrossRef Medline

Justice NJ, Yuan ZF, Sawchenko PE, Vale W (2008)

Type 1 corticotropin-releasing factor receptor expression reported in BAC transgenic mice: implications for reconciling ligand-receptor mismatch in the central corticotropin-releasing factor system. J Comp Neurol 511:479-496. CrossRef Medline

Karl A, Schaefer M, Malta LS, Dörfel D, Rohleder N, Werner A (2006) A meta-analysis of structural brain abnormalities in PTSD. Neurosci Biobehav Rev 30:1004-1031. CrossRef Medline

Kessler RC, Berglund P, Demler O, Jin R, Merikangas KR, Walters EE (2005) Lifetime prevalence and age-of-onset distributions of DSM-IV disorders in the National Comorbidity Survey Replication. Arch Gen Psychiatry 62:593-602. CrossRef Medline

Kim JJ, Diamond DM (2002) The stressed hippocampus, synaptic plasticity and lost memories. Nat Rev Neurosci 3:453-462. CrossRef Medline

Kramár EA, Chen LY, Brandon NJ, Rex CS, Liu F, Gall CM, Lynch G (2009) Cytoskeletal changes underlie estrogen's acute effects on synaptic transmission and plasticity. J Neurosci 29: 12982-12993. CrossRef Medline

Lehrner A, Daskalakis N, Yehuda R (2016) Cortisol and the hypothalamic-pituitary-adrenal axis in PTSD. In: Posttraumatic stress disorder: from neurobiology to treatment. Hoboken, NJ: John Wiley \& Sons.

Maras PM, Molet J, Chen Y, Rice C, Ji SG, Solodkin A, Baram TZ (2014) Preferential loss of dorsal-hippocampus synapses underlies memory impairments provoked by short, multimodal stress. Mol Psychiatry 19:811-822. CrossRef Medline

Samuelson KW (2011) Post-traumatic stress disorder and declarative memory functioning: a review. Dialogues Clin Neurosci 13:346-351. Medline

Sandrini M, Cohen LG, Censor N (2015) Modulating reconsolidation: a link to causal systemslevel dynamics of human memories. Trends Cogn Sci 19:475-482. CrossRef Medline

Shakespeare-Finch J, Lurie-Beck J (2014) A metaanalytic clarification of the relationship between posttraumatic growth and symptoms of posttraumatic distress disorder. J Anxiety Disord 28: 223-229. CrossRef Medline

Vogel S, Schwabe L (2016) Learning and memory under stress: implications for the classroom. Sci Learn 1:16011. CrossRef 